\title{
Study on Islanding Strategy for Fault Recovery of Distribution Network with Micro Grid
}

\author{
Yang Lijun ${ }^{1, a}$, Lv Xuejiao ${ }^{1, b}$, Ma Cong ${ }^{2, c}$,Wei Lingling ${ }^{1, d}$, Chang Xueting ${ }^{1, \text { e }}$ \\ ${ }^{1}$ Key Lab of Power Electronics for Energy Conservation and Motor Drive of Yanshan University, \\ Qinhuangdao 066004, Hebei Province, China \\ ${ }^{2}$ State Grid Hebei Electric Power Company Economic and Technical Research Institute, \\ Shi jiazhuang 050000, Hebei Province, China

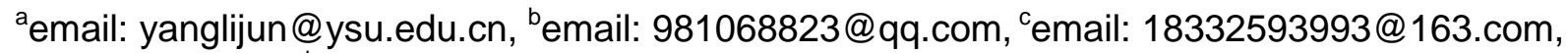 \\ demail: 1040175010@qq.com, email: 837687902@qq.com
}

Keywords: Renewable energy; Micro grid; Dynamic importance degree; Islanding search

\begin{abstract}
In order to meet actual situations for fault recovery of distribution network with micro grid, a strategy that micro grid runs firstly with important loads in islanding mode is studied. Generating islanding, the dynamic changes of the various DGs and loads in non-fault zone should be considered, and the dynamic importance degree of each load will be calculated as the inspired conditions for the subsequent islanding search. Whether the load adds to islanding depends on the dynamic importance degree of the load in this paper. The reliability of islanding operation will be analyzed in islanding search. The proposed strategy can control the direction of islanding search and give priority to the recovery of important loads. Also, the balance between the stable islanding and the maximum use of renewable energies can be ensured. The effectiveness of the proposed strategy will be verified by the improved 33-bus system.
\end{abstract}

\section{Introduction}

With the continued consumptions of fossil energy, the rational use of renewable energies has become an indispensable way to solve the energy crisis and strengthen environmental protection [1]. Currently, the fault recovery of distribution network has been greatly studied [2] [3]. Different minimum spanning tree algorithms for the islanding problem of distribution network with distributed powers have been studied [4] [5]. But these are not well applied to distribution network with micro grid containing renewable energies. Literature [6] adopts a method based on a rooted tree search. That is a simple and effective method for islanding search. However, the importance degrees of loads, the various fluctuations of distributed power supply and loads are different at different time.

For fault recovery of distribution network, the traditional approach method of micro grid is that the system firstly separates from main network and operates in islanding mode after failure is detected. Then, the $\mathrm{V} / \mathrm{f}$ droop control method will be used to guarantee the voltage amplitude and frequency [7] [8]. Thus, the loads of micro grid can operate in the normal mode by the proposed method in most cases. However, it is likely to encounter a situation where the non-critical loads within the micro grid operate in the normal mode and the important loads out of the micro grid lose power. In this paper, according to the recovery requirements of distribution network, a fault recovery strategy that micro grid operates firstly with the important loads in islanding mode is built under the fault conditions. Through the proposed strategy, the important loads closed to micro gird will be preferentially recovered and the renewable energies also can be fully utilized. At the same time, it can avoid the situation where the ability of power supply of main grid is limited and the power supply of important loads is interrupted. Thus, a recovery strategy on the rational use of renewable energies in the micro grid has an important meaning. 


\section{Related restrictions and evaluation indexes of islanding strategy}

Prior principle of load value.

After failures occur, a largest dynamic load value of recovery should be ensured by the adopted islanding strategy. And the dynamic load value will be determined by the importance degree and the dynamic power value of loads.

\section{Stability restrictions.}

1) Power balance in islanding

$$
\sum_{i \in V_{s}} P_{a v w i}+\sum_{j \in V_{s}} P_{a v e j}-\sum_{k \in V_{s}} P_{a v k} \geq 0
$$

It is that the sum of dynamic average output power of all the wind turbines and PVs in the islanding $V_{s}$ is not less than the sum of the dynamic average output power of loads in the fault period. $P_{a v w}, P_{a v e}, P_{a v k}$ are the dynamic average output power of each fan, PV and load, respectively.

2) Capacity restrictions of line and transformer

$$
I_{\max }<I_{e}
$$

In the type: $I_{\max }$ represents the maximum current on the line and transformer; $I_{e}$ is the rated current on the line and transformer.

\section{Strategy evaluation indexes.}

Based on the Sequential Monte Carlo simulation method [9] and the random discrete data provided by each generation unit and load model, this paper adopts the following indexes to analyze and ensure the reliability of system. Also, the security can be well ensured.

Energy Does Not Supplied for Islanding (EDNSI) can be obtained by equation (3).

$$
\lambda_{\mathrm{EDNSI}}=\sum_{i=1}^{n} P_{\text {sqdi }}
$$

In the type: $P_{s q d i}$ is the loss of power in the step $i ; n$ is the total number of the islanding simulated steps; $\lambda_{\text {EDNSI }}$ is the total loss of power in islanding process.

First Loss Of Power Time (FLOPT) can be obtained by equation (4).

$$
T_{\mathrm{FLOPT}}=\frac{1}{m} \sum_{i=1}^{m} t_{i}
$$

In the type: $t_{i}$ is the first loss of power time in the islanding simulated operation; $m$ is the total number of simulation operations; $T_{\text {FLOPT }}$ is the expectation of operated time under the undiminished loads for islanding.

The probability of the undiminished loads for islanding can be calculated by equation (5).

$$
P_{\mathrm{nl}}=\frac{N_{\mathrm{cg}}}{N}
$$

In the type: $N_{c g}$ is the number of times of the uninterrupted power supply; $N$ is the total number of simulation operations.

\section{Strategy evaluation standard.}

The islanding is to take advantage of the power margin of micro grid and integrate more important loads into islanding under failures for distribution network with micro grid. The expression of strategy evaluation standard is as follows:

$$
F_{j z}=\sum_{k=1}^{n} M_{k} P_{a v k}
$$

In the type: $F_{j z}$ is the total value of recovered loads in islanding; $M_{k}$ is the fitness of value for node $k$, which can be set to $10,5,1$ according to the level of load. $P_{a v k}$ is the dynamic average 
power of node $k$ in the fault period.

\section{Model and process of loads and powers}

\section{Determination of load importance degree.}

Loads are divided into heavy loads, light loads, service loads and live loads in this paper. Using the fuzzy C-means clustering and the cubic spline interpolation method, the historical data can be turned into the normalized fitted functions [10].

The dynamic importance degree $\lambda$ of fitted function for load $a$ can be calculated as follows.

$$
\lambda=\frac{\lambda_{a}\left(t_{2}-t_{1}\right)}{P_{a} \int_{t_{1}}^{t_{2}} f_{a}(t)}
$$

In the type: $\lambda_{a}$ is the importance degree of parameter determined by the load importance degree, the corresponding values of the first level load, the secondary level load and the three level load are respectively $10,5,1 ; t_{1}$ is the starting time for the fault; $t_{2}$ is the completed repair time for the fault; $f_{a}(t)$ is the selected normalized fitted function according to the type of loads. By comparing this load with the maximum load in lost power zone, the $P_{a}$ can be calculated as follows:

$$
P_{a}=\frac{10 P}{P_{\max }}
$$

In the type: $P$ is the rated power of load $a ; P_{\max }$ is the maximum rated power of loads in non-fault zone; $\boldsymbol{P}_{\boldsymbol{a}}$ can be set between 0 and 10, but not 0 .

According to the classification of loads, the average power $P_{\text {ava }}$ of load $a$ can be calculated as follows.

$$
P_{a v a}=P \int_{t_{1}}^{t_{2}} f_{a}(t)
$$

In the type: $P$ is the rated power of load $a ; t_{1}$ is the starting time for the fault; $t_{2}$ is the completed repair time for the fault; $f_{a}(t)$ is the selected normalized fitted function according to type of loads.

\section{Renewable energy process of micro grid.}

According to the analysis of historical statistical data, the probability distribution of wind speed can be expressed by Weibull distribution. This paper adopts Beta distribution to simulate the probability model of PV and Markov transition matrix to simulate the weather change [11].

\section{Energy storage device model.}

In this paper, the energy storage device adopts the lead-acid batteries. In order to better meet the actual situations, this paper refers to the maximum charging power, the maximum discharging power, capacity and other indicators of two-pool model to simulate the storage device [12]. The energy storage device acts as the secondary power unit and adopts the PQ control mode in the simulation operation.

\section{Islanding rules and procedures}

In order to meet the actual situations for fault recovery of distribution network, islanding strategy is established in this paper. Through adopting the proposed strategy, the islanding dynamic value and islanding reliability also can be effectively guaranteed. An actual simplified diagram of distribution network is showed in Fig. 1.

\section{Adopting different islanding modes depending on different circumstances.}

1) When the sum of lost power in non-fault zone is less than the dynamic power generated by renewable energies of micro grids, it is not necessary to search islanding. All the micro grids in non-fault zone operate with the main grid. When the islanding reliability is not met the demands and in order to ensure the stability, the loads with dynamic minimum importance degree should be 
cut. This case will not be discussed in the following text.

2) When the sum of lost power in non-fault zone is more than the dynamic power, and in order to recover much loads of greater value, all the three level loads in micro grids should be disconnected. Then, the following proposed islanding search will be used.

3) When the three level loads have disconnected in a failure of micro grid, and due to it cannot meet their operational requirements, which is known as non-output of micro grid, loads of micro grid will be cut according to the dynamic importance degree, and until it meets the requirements of the islanding reliability. The weight value is set to 0 and these loads are not participated in the process of generated islanding.

\section{Islanding model.}

Through the above text, the connected graph model of distribution network will be established, and the islanding problem of distribution network with micro grid will be converted to the sake of minimum spanning tree problem. Graph is a structure with complex nonlinear data and includes nodes collection and edges collection. Graph $G$ can be defined as follows: vertex set and edge set are respectively $V(G)$ and $E(G) . T=\left(U, T_{E}\right)$ is a minimum spanning tree of $G$; $U$ is the vertices set of $T ; T_{E}$ is the edge set of $T$; the initial values of $U$ and $T_{E}$ are the empty set. Set $E_{1}=\left\{\left(v_{i}, v_{j}\right)\right.$ $\left.W_{i j} i \in U \& j \notin U\right\}$ and $E_{2}=\left\{\left(v_{i}, v_{j}\right) W_{i j}, i \in U \& j \notin U\right\}$, which are the candidate selected sets; $E_{1}$ and $E_{2}$ are the subsets of $E$, only one vertex of $E_{1}$ and $E_{2}$ is belong to the set $U$. Set $V_{1}=\left\{v_{p} \mid 0 \leq i \leq m\right.$ - $1, m \geq 0\} ; V_{1}$ is the nodes collection of islanding; $v_{p}$ is the dynamic power of islanding; $m$ is the total number of micro grids. A connected graph of distribution network is shown in Fig.2.

\section{Process of islanding search.}

Specific process of islanding search is as follows:

1) The largest dynamic importance degree node is selected as the root node from and adds to $U$.

2) Applying the equation (1) to verify the dynamic power constraints, if it meets the constraints, the collections $T, E_{1}$ and $E_{2}$ should be updated. An edge of largest value will be selected to join in the islanding.

3) Repeat step 2) until $V$ includes all the nodes of $U$ or it cannot meet the dynamic power constraints.

4) After an islanding search has been completed, the following search should be completed according to step2), until all the able output micro grids join in islanding.

5 ) Whether two nodes of an edge of set $E$ exist in the nodes set of two islands, if it is, this edge should be connected and the two islands will be integrated into a big island and turns to step 1); else, next step.

6) Through the Monte Carlo method to verify the proposed strategy, the islanding reliability can be obtained. If it meets the requirements, the strategy will be carried out; else, next step.

7) After completing the search of all the able output micro grids, the dynamic importance degree of all the three level loads in each network and the loads of islands should be compared in reverse direction. If it is greater than islanding loads, the islanding loads should be cut and replaced by the three level loads. If the removal loads can result in a large islanding split, the loads will not be replaced.

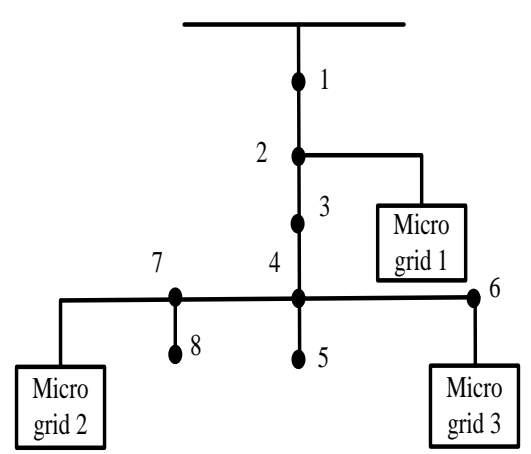

Fig. 1 An actual simplified diagram

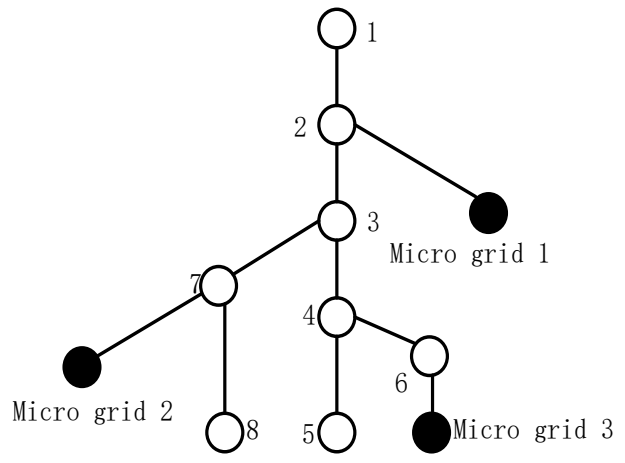

Fig. 2 Connected graph 


\section{Case analysis}

The proposed method is tested on the improved bus system IEEE33 shown in Fig. 3. Assuming that branch 1-2 occurs a fault at 8:00 am and the duration time is $2 \mathrm{~h}$.

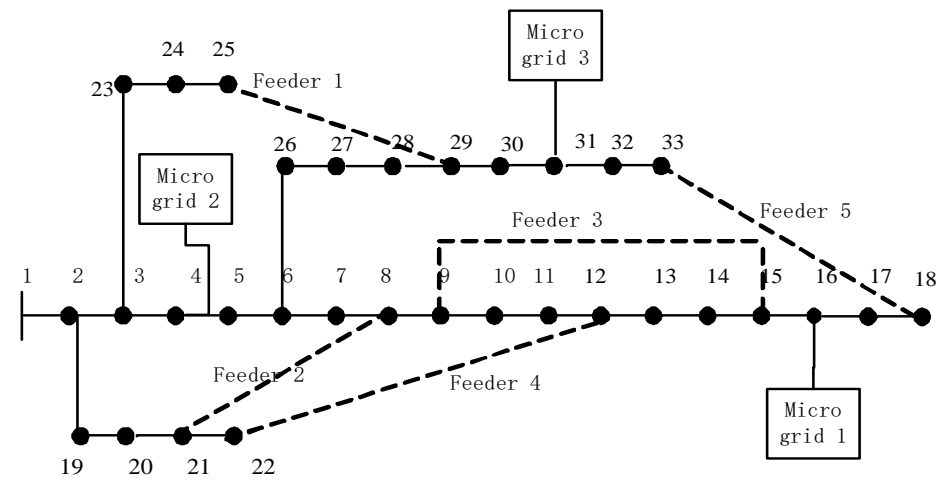

Fig.3 Improved 33 node distribution network with micro grids

The specific power supplies of each micro grid are shown in Table 1. The load levels are shown in Table 2 and the load attributes are listed in Table 3.

Table. 1 power supplies of micro grids

\begin{tabular}{cccccc}
\hline $\begin{array}{c}\text { Micro grid } \\
\text { number }\end{array}$ & PV rated power & Wind rated power & $\begin{array}{c}\text { Important loads } \\
\text { rated power }\end{array}$ & $\begin{array}{c}\text { Three level loads rated } \\
\text { power }\end{array}$ & Storage device energy \\
\hline 1 & $300 \mathrm{~kW}$ & $1500 \mathrm{~kW}$ & $400 \mathrm{~kW}$ & $600 \mathrm{~kW}$ & $200 \mathrm{kWh}$ \\
2 & $500 \mathrm{~kW}$ & 0 & $110 \mathrm{~kW}$ & $400 \mathrm{~kW}$ & $150 \mathrm{kWh}$ \\
3 & $500 \mathrm{~kW}$ & 0 & $240 \mathrm{~kW}$ & $400 \mathrm{~kW}$ & $200 \mathrm{kWh}$ \\
\hline
\end{tabular}

Table. 2 load levels

Table. 3 load attributes

\begin{tabular}{cc}
\hline Load levels & Node number \\
\hline First level & $2,11,12,31,32$ \\
Secondary level & $5,13,14,25$ \\
\hline
\end{tabular}

\begin{tabular}{cc}
\hline Load attributes & Node number \\
\hline Service loads & $3,7,13,17,27$ \\
Live loads & $4,5,6,10,11,12,16,29$ \\
Light loads & $2,8,9,15,30,31$ \\
Heavy loads & $14,25,26,28$ \\
\hline
\end{tabular}

Using the method to search islanding, the initial strategy for fault recovery should meet the islanding power balance and the islanding strategy is shown in Table 4.Through analyzing the reliability of islanding 1 , the first outage time is $1.8 \mathrm{Min}$, the expectation of power shortage is $474 \mathrm{kWh}$ and the probability of the secondary failure that islanding does not occur is $0 \%$. For the islanding 2, the first outage time is $107.3 \mathrm{Min}$, the expectation of power shortage is $13 \mathrm{kWh}$ and the probability of the secondary failure that islanding does not occur is $92 \%$. Obviously, islanding 1 does not meet the reliability requirements. In order to meet the stability indexes, loads should be cut, according to the dynamic importance degree of boundary nodes in the sequence from small to large to make modifications of the proposed strategy, and the results are shown in Table 5.

Table. 4 Islanding strategy

\begin{tabular}{cc}
\hline Islanding number & Islanding strategy \\
\hline & Micro grid 1, Micro grid 2, Load \\
1 & $4,5,6,7,8,9,10,11,12,13$, \\
& $14,15,16,17,18,23,24,25,26,27,28$ \\
2 & Micro grid 3, Load 31,32 \\
\hline
\end{tabular}

Table.5 Execution results

\begin{tabular}{cc}
\hline Islanding number & Islanding strategy \\
\hline 1 & Micro grid 1, Load \\
& $9,10,11,12,13,14,15,16,17,18$ \\
2 & Micro grid 2, Load 3,4,5,23 \\
3 & Micro grid 3 Load 31 32 \\
\hline
\end{tabular}

From the results, we can know that the rational islanding, the evaluation indexes of islanding 
strategy to verify the reliability and revise the unreliable strategy can reduce the loss of important load power, restore much critical loads and obtain a better reliable system.

\section{Conclusion}

When distribution network with micro grids occurs fault, the traditional fault recovery is that micro grids separate from the main grid in islanding operation mode. Through the proposed strategy of islanding search, the important loads sequentially are included in islanding and supplied power by micro grids. The proposed islanding strategy adopts the method that the system cuts the three level loads and expands external power supply capacity of micro grids in this paper. Therefore, the lost power possibility of important loads, which are caused by the insufficient capacity of power supply for main grid, will be reduced to a large extent. Also, the possibility of heavy economic losses, which are caused by the important lost power loads, and the occurrence times of fault will be reduced. The islanding evaluation indexes are proposed to verify the reliability of obtained strategy, ensure a successful islanding operation and prevent secondary failure.

\section{Acknowledgement}

The research was sponsored by the Nature Science Foundation of Hebei Province (Project No. E2014203254).

\section{References}

[1] Mirbach T,Ohrem S,Schild S,etal.Impact of a significant share of renewable energies on the European power generation system[C].7th International Conference on the European Energy Market, Crete,Greece, 2010.

[2] LIU li,CHEN xuefeng,ZHUO denghui.Fault recovery situation and prospect in smart distribution network[J]. Power System Protection and Control,2011,39(13):148- 154.

[3] Gong weizheng,Fang xinyan.Fault recovery algorithm study of distribution network based on hybrid encoding[J]. Power System Protection and Control,2012,40(6):104-108.

[4] DONG xiaofeng,LU yuping.Distribution generation islanding method based on improved Prim algorithm[J].Power System echnology,2010,34(9):195- 201.

[5] LIU zongqi,BAO qiaomin,SUN chunshan,et al.Distribution network islanding algorithm with distributed generation based on improved Kruskal algorithm[J].Transations of China Electrotechnical Society.2013,28(9):164-171.

[6] DING lei,PAN zhencun,CONG wei.Distributed generation island search based on rooted tree [J].Proceedings of the CSEE, 2008, 28(25): 62-67.

[7] Huang Wei,Sun Changhui,Wu Ziping,et al.A review on microgrid technology containing distributed generation system[J].Power System Technology,2009,33(9):14-18.

[8] LI fudong,WU min.Improved control strategy for load distribution in micro-grid island mode[J]. Proceedings of the CSEE.2011,31(13):18-25.

[9] GE shaoyun,WANG haoming,XU shuo.Distributed scenery storage power system reliability evaluation based on Monte Carlo simulation[J].Power System Technology. 2012,36(4):39-44.

[10] JIANG shigong,LI yan,WANG wei.A energy management Strategy under micro-grid island operation[J].Transations of China Electrotechnical Society.2014,29(2):130-135.

[11] LI chengxi,YANG qiang,YAN wenjun.Microgrid island dynamic operating strategy with distributed photovoltaic Power[J].Power System Protection and Control.2013,41 (8):99-105.

[12] XIE kaigui,WANG an,HU bo.wind/diesel/hybrid storage system reliability assessment considering energy storage device running strategy[J].Power System Protection and Control.2012,40(9): 1-7. 